Article

\title{
Large Optical Nonlinearity of the Activated Carbon Nanoparticles Prepared by Laser Ablation
}

\author{
Yasin Orooji ${ }^{1, *(\mathbb{D})}$, Hamed Ghanbari Gol ${ }^{2}$, Babak Jaleh ${ }^{2, * \mathbb{D}}$, Mohammad Reza Rashidian Vaziri ${ }^{3, *(\mathbb{D})}$ \\ and Mahtab Eslamipanah ${ }^{2}$
}

1 College of Materials Science and Engineering, Nanjing Forestry University, Nanjing 210037, China

2 Department of Physics, Faculty of Science, Bu-Ali Sina University, Hamedan 65174, Iran; hamed.gh053@gmail.com (H.G.G.); mahtabes740@gmail.com (M.E.)

3 Photonics and Quantum Technologies Research School, Nuclear Science and Technology Research Institute, Tehran P.O. Box 14399511-13, Iran

* Correspondence: yasin@njfu.edu.cn (Y.O.); jaleh@basu.ac.ir (B.J.); rezaeerv@gmail.com (M.R.R.V.); Tel.: +86-2585428071 (Y.O.); +98-9122114707 (B.J.); Fax: +86-2585427653 (Y.O.); +98-8138381470 (B.J.)

Citation: Orooji, Y.; Ghanbari Gol, H.; Jaleh, B.; Rashidian Vaziri, M.R.; Eslamipanah, M. Large Optical

Nonlinearity of the Activated Carbon Nanoparticles Prepared by Laser Ablation. Nanomaterials 2021, 11, 737. https://doi.org/10.3390/ nano11030737

Academic Editor: Giuliana Faggio

Received: 17 February 2021

Accepted: 11 March 2021

Published: 15 March 2021

Publisher's Note: MDPI stays neutral with regard to jurisdictional claims in published maps and institutional affiliations.

\begin{abstract}
Carbon nanoparticles (CNPs) with high porosity and great optical features can be used as a luminescent material. One year later, the same group investigated the NLO properties CNPs and boron-doped CNPs by $532 \mathrm{~nm}$ and $1064 \mathrm{~nm}$ laser excitations to uncover the underlying physical mechanisms in their NLO response. Hence, a facile approach, laser ablation technique, was employed for carbon nanoparticles (CNPs) synthesis from suspended activated carbon (AC). Morphological properties of the prepared CNPs were studied by transmission electron microscopy (TEM) and scanning electron microscopy (SEM). UV-Vis and fluorescence (FL) spectra were used to optical properties investigation of CNPs. The size distribution of nanoparticles was evaluated using dynamic light scattering (DLS). The nonlinear optical (NLO) coefficients of the synthesized CNPs were determined by the Z-scan method. As a result, strong reverse saturable absorption and self-defocusing effects were observed at the excitation wavelength of $442 \mathrm{~nm}$ laser irradiation. These effects were ascribed to the presence of delocalized $\pi$-electrons in AC CNPs. To the best of our knowledge, this is the first study investigating the NLO properties of the AC CNPs.
\end{abstract}

Keywords: activated carbon; carbon nanoparticles; laser ablation; nonlinear optical material

\section{Introduction}

Carbon is one of the most standout elements on the earth and can be formed in different forms such as carbon nanoparticles, carbon nanotube, and graphene [1,2]. Recently, carbon-based nanomaterials, including carbon nanotubes (CNTs), CNPs, and graphene, have been noticed due to their superior properties like high porosity, high adsorption capacity, nontoxicity, adjustable morphology, and simple preparation [3,4]. CNPs with small size, good biocompatibility and chemical stability, high hydrophilicity, and great flexibility show interesting optical properties known as luminescent materials [5,6]. Their great conductivity and electrochemical activity and high surface area have caused to application of them in energy devices like batteries and supercapacitors [7-10]. It is worth mentioning that CNPs are more interested than other carbon nanostructures due to their facile and low-cost synthetic approaches containing physical and chemical methods. Thermal/hydrothermal [11], electrochemical synthesis [12], and acidic oxidation [13] are some CNPs chemical synthesis methods. Since chemical methods may be damaging to environmental, physical methods such as plasma treatment [14] and laser ablation [15] can be used as a suitable alternative for chemical methods.

Laser ablation in liquid (LAL) media is one of the simplest ecofriendly methods for CNPs synthesis [15]. In the LAL process, size and morphology of the produced NPs depend on both the laser parameters (wavelength, frequency, power, etc.) and the used liquid 
medium [16]. This promising method has a number of advantages such as decreasing the effect of heat on the target, lowering the synthesis time, and using clean environments without any chemical pollutions $[17,18]$. Furthermore, the synthesized NPs disperse in the liquid media and produce colloidal suspensions during the LAL process, which can simplify the utilization of the produced NPs for in vivo applications $[17,19,20]$. Some researchers have reported the synthesis of CNPs using the LAL process of suspended particles in liquid as targets. For example, Hu et al. synthesized luminescent CNPs by laser ablation of dispersed carbon black in poly(ethylene glycol) solution [21].

Moreover, Małolepszy et al. used the laser ablation process for the synthesis of fluorescent CNPs from suspended reduced graphene oxide in deionized water, isopropyl alcohol (IPA), acetone, and PEG200 liquids [22]. Briefly speaking, there are three steps in the LAL process of suspended particles in liquid as targets: first, when the pulsed laser is focused and the radiation is started, it penetrates into the suspended particles [23]. In the second step, the laser-induced melting-evaporation occurs for the large particles and produces atoms and molecules. Afterwards, atoms and molecules aggregate and form nanostructures with different shapes and sizes [24]. In the third step, the thermal ejection of electrons occurs from the nanostructure surface that leads to the formation of positive charges which has as a result the laser-induced Coulomb explosion. Electrostatic repulsion between different parts of the primary particles arises and causes the production of finer particles due to the crushing of the larger ones [24]. AC is an ideal family of carbon materials with porosity spaces which are surrounded with carbon atoms and has special properties such as high surface area, large pore volumes, good thermostability at high temperatures, and small pore sizes $(<1 \mathrm{~nm})$ properties [25-27]. Because of its unique properties, AC can be used to CNPs preparation.

In semiconducting or insulating materials, single-photon linear absorption may occur if the incident photon energy be of the bandgap energy order. This is a constant effect independent of the incident light intensity. When this single-photon process becomes intensity-dependent, two different effects of saturable absorption or reverse-saturable absorption can occur. In the case of a two-level material, larger or smaller absorption of the excited state concerning the ground state leads to reverse-saturable or saturable absorption effects, respectively. In a saturable absorber, the absorption coefficient decreases with increasing the light intensity; while in a reverse-saturable absorber, the situation is exactly reverse because of the ground state depletion. At high-intensity optical fields, there is also the possibility of bandgap bridging by synchronous absorption of more than one photon, with the condition that sum of the photon energies exceeds the energy gap. These kinds of NLO processes are called multiphoton absorption.

In the simplest case, just two photons are involved, and the process is known as twophoton absorption. Materials with different dominant NLO processes have attracted a lot of interest. For instance, saturable absorbers are used for Q-switching of high-power lasers [28]. Reverse-saturable absorbers and materials with two- and multi-photon absorptions are also used as optical limiters and in nonlinear microscopy, 3D imaging, and nonlinear spectroscopy [29]. In order to design and develop more efficient NLO devices, great attention has turned to find materials with larger NLO response in recent years [30-32].

In quest of new nonlinear optical (NLO) materials besides graphenes, fullerenes, and carbon nanotubes, little is known about the NLO properties of CNPs [33]. Recently, it was noticed that CNPs possess comparable NLO properties to other types of NLO materials, such as perovskites and antimonenes [34]. They can be easily and inexpensively synthesized and, hence, are often regarded as favorable materials for NLO devices. Furthermore, they have abundant delocalized-electrons that ensure their good NLO performance and make them appropriate candidates in such applications [35]. In 2014, it was noticed that CNPs exhibit negative nonlinear refractivity using a $532 \mathrm{~nm}$ laser source by the Z-scan method [33]. One year later, the same group investigated the NLO properties CNPs and boron-doped CNPs by $532 \mathrm{~nm}$ and $1064 \mathrm{~nm}$ laser excitations to uncover the underlying physical mechanisms in their NLO response [36]. Following these two pioneering works, subsequent studies in many other 
groups, especially in recent years, have focused on investigating the NLO properties of CNPs and CNPs doped with other materials [34,35,37-41]. However, to the best of our knowledge, there is no study on investigating the NLO properties of the AC CNPs, and much work is required in this area.

Table 1 summarizes the other reports based on the used synthesis method of CNPs, their size range, and the corresponding possible applications or interesting optical properties.

Table 1. Comparison of the synthesized carbon nanoparticles (CNPs) size by different methods.

\begin{tabular}{|c|c|c|c|c|}
\hline Nanostructure & $\begin{array}{l}\text { CNPs Synthesis } \\
\text { Method }\end{array}$ & CNPs Size (nm) & Properties and Application & Ref. \\
\hline Carbon nanoparticles & LAL & $4-20$ & $\begin{array}{l}\text {-Good photoluminescence } \\
\text {-Can be used for bioimaging }\end{array}$ & [42] \\
\hline $\begin{array}{l}\text { Nitrogen-doped carbon } \\
\text { nanodots (N-CND) and } \\
\text { Starch Derived Carbon } \\
\text { Nanodots (C-CND) }\end{array}$ & $\begin{array}{l}\text { microwave-assisted } \\
\text { hydrothermal } \\
\text { precursor carbonization }\end{array}$ & $\begin{array}{l}2.0 \pm 0.24(\mathrm{C}-\mathrm{CND}) \text { and } \\
2.4 \pm 0.25(\mathrm{~N}-\mathrm{CND})\end{array}$ & $\begin{array}{l}\text {-High photoluminescence quantum } \\
\text { yield } \\
\text {-Long-term stability } \\
\text {-Having stable emission }\end{array}$ & [43] \\
\hline $\begin{array}{l}\text { Boron-doped carbon } \\
\text { dots }\end{array}$ & Microwave heating & $2-6$ & $\begin{array}{l}\text {-Robust blue fluorescence under UV } \\
\text { excitation } \\
\text {-Large nonlinear optical }\end{array}$ & [36] \\
\hline $\begin{array}{l}\text { Nitrogen-doped carbon } \\
\text { nanoparticles }\end{array}$ & Microwave oven & $5.5 \pm 1.5$ & -Highly fluorescent & [44] \\
\hline Carbon nanoparticles & Thermal pyrolysis & $20-50$ & $\begin{array}{l}\text {-Highly fluorescent } \\
\text {-Excellent photoluminescent } \\
\text {-Used as a metal sensing probe }\end{array}$ & [45] \\
\hline Carbon nanoparticles & Thermal carbonization & - & $\begin{array}{l}\text {-Synthesized nanoscale particle size } \\
\text {-Used as a supercapacitor } \\
\text {-Highly specific capacitance and } \\
\text { excellent long-term cycle stability }\end{array}$ & [9] \\
\hline Carbon nanoparticles & $\begin{array}{l}\text { Stirring and reflux } \\
\text { method }\end{array}$ & 115 & - Improved release of the drugs & [46] \\
\hline Carbon nanoparticles & $\begin{array}{c}\text { Dehydration of } \\
\text { hyaluronic acid and } \\
\text { carbonized hyaluronic } \\
\text { acid }\end{array}$ & $<20$ & $\begin{array}{l}\text {-Flexibility } \\
\text {-Biocompatible and low cytotoxicity } \\
\text {-Used for in vitro and in vivo } \\
\text { bioimaging }\end{array}$ & [47] \\
\hline Carbon Nanoparticles & $\begin{array}{l}\text { Hydrothermal } \\
\text { carbonization and } \\
\text { high-temperature } \\
\text { annealing }\end{array}$ & 120 & $\begin{array}{l}\text {-Used as an anode for lithium-ion } \\
\text { Battery }\end{array}$ & [48] \\
\hline Carbon Nanoparticles & $\begin{array}{l}\text { Thermally-assisted } \\
\text { carbonization }\end{array}$ & - & $\begin{array}{l}\text {-synthesized nanoparticles in small } \\
\text { size } \\
\text {-Strong blue luminescence } \\
\text {-Used for sensing of metal ions }\end{array}$ & [49] \\
\hline Carbon dots & Microwave oven & $<10$ & $\begin{array}{l}\text {-Highly biocompatible } \\
\text {-Great fluorescent property } \\
\text {-Used for cell imaging }\end{array}$ & {$[50]$} \\
\hline Carbon Nanoparticles & $\begin{array}{l}\text { acid treatment of } \\
\text { naturally occurring } \\
\text { d-glucose followed by } \\
\text { heating }\end{array}$ & $<5$ & $\begin{array}{l}\text {-Used for sensing of metal ions } \\
\text {-Used for in vivo imaging }\end{array}$ & [51] \\
\hline
\end{tabular}


Table 1. Cont.

\begin{tabular}{cccc}
\hline Nanostructure & $\begin{array}{c}\text { CNPs Synthesis } \\
\text { Method }\end{array}$ & CNPs Size (nm) & Properties and Application \\
\hline Carbon Nanoparticles & $\begin{array}{c}\text { Hydrothermal } \\
\text { treatment }\end{array}$ & $20-40$ & $\begin{array}{l}\text { - Highly photoluminescent and } \\
\text { photo-stability } \\
\text {-Low toxicity and good } \\
\text { biocompatibility } \\
\text {-Used for in vitro and in vivo } \\
\text { imaging }\end{array}$ \\
\hline Carbon Nanoparticles & Light-induced process & 40 & $\begin{array}{l}\text {-Used for sensing of metal ions } \\
\text {-Used as a photocatalyst for } \\
\text { hydrogen evolution }\end{array}$ \\
\hline $\begin{array}{l}\text { Nitrogen-doped carbon } \\
\text { quantum dots }\end{array}$ & Microwave-assisted & $2.47 \pm 0.84$ & $\begin{array}{l}\text {-Size and surface controllable of } \\
\text { synthesized NPs } \\
\text {-Fluorescent emission } \\
\text {-Excellent solubility in water }\end{array}$ \\
\hline Carbon nanoparticles & Laser ablation in \\
n-heptane & 23.84 & $\begin{array}{l}\text {-Large optical nonlinearities with } \\
\text { 442 nm laser radiation }\end{array}$ \\
\hline
\end{tabular}

Herein, CNPs were prepared by LAL on the suspended AC in heptane medium. Structural, optical, and NLO properties of the prepared CNPs were studied. Employing the Z-scan method, it is shown that CNPs exhibit large optical nonlinearities by excitation with $442 \mathrm{~nm}$ laser radiation.

\section{Materials and Methods}

\subsection{Materials and Instruments}

Commercial granular AC (Merck, Germany) with a mean diameter of $1.5 \mathrm{~mm}$ andspecific surface area of $961.1 \mathrm{~m}^{2} / \mathrm{g}$ was utilized in this work [55]. A fiber laser (RFL-P30Q, China) with the wavelength of $1064 \mathrm{~nm}$, maximum power of $30 \mathrm{~W}$, and frequency of $20 \mathrm{kHz}$ was used for the LAL process. To obtain homogenous suspension of AC and n-heptane, the ultrasonic bath (DSA100-SK2-4.0L, China) with voltage of $220 \mathrm{~V}$, power of $100 \mathrm{~W}$, and frequency of $40 \mathrm{kHz}$ was utilized. The fabricated colloidal samples' optical properties were perused using ultraviolet-visible spectroscopy (UV-Vis, JASCO V-630, Japan) and fluorescence spectroscopy (Perkin Elmer LS50B, United Kingdom) techniques. DLS (Zetasize Nano ZS, Malvern) technique was used to determine the size distribution profile of CNPs. SEM (TESCAN MIRA3-XMU, Brno-Kohoutovice, Czech Republic) and TEM (CM120, Netherlands) images were used for morphological investigation of nanoparticles. Energy-dispersive X-ray spectroscopy (EDX) assay was used to determine the presence of elements in CNPs. NLO coefficients of the fabricated samples were measured by the Z-scan method.

\subsection{Laser Ablation of Suspended AC}

The laser ablation was carried out in n-heptane medium. To this aim, $5 \mathrm{mg}$ of AC was dispersed in $10 \mathrm{~mL}$ of n-heptane solvent using $20 \mathrm{~min}$ ultrasonication. Afterwards, the dispersion was exposed to laser irradiation for $130 \mathrm{~min}$. The color of suspension was changed to yellowish during the laser irradiation, which confirmed the CNPs formation. Finally, the irradiated sample was filtered and dried. Figure 1 illustrates the schematic representation of the synthesis process. 


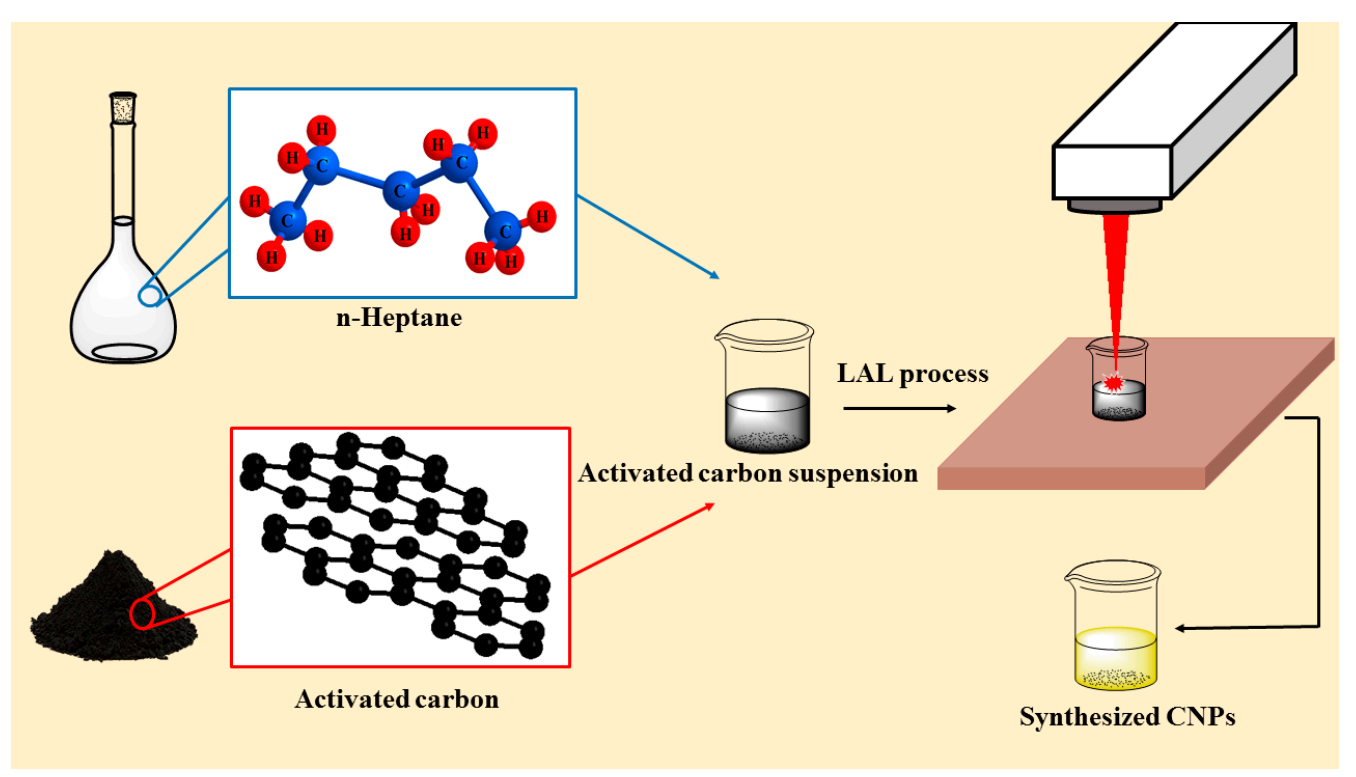

Figure 1. Schematic representation of the adopted experimental procedure for preparation of CNPs.

\subsection{Z-Scan Measurements}

The well-known Z-scan method was used for measuring the NLO coefficients. Z-scan is a rapid, easy, and sensitive method for measuring the NLO coefficients of materials $[56,57]$. This method has attracted much interest and is being extensively used to determine the NLO coefficients of materials [58]. Figure 2 depicts the scheme of the used experimental Z-scan setup in this study. The beam splitter divides the emitted laser beam (CW He-Cd, $442 \mathrm{~nm}$, $150 \mathrm{~mW}$ ). The first power meter (power meter 1) measures the power of the first half as the reference power. A converging lens $(f=25 \mathrm{~cm})$ focuses the other half of the laser beam (spot size $\sim 20 \mu \mathrm{m}$ at focus). This divided part of the laser beam passes respectively through the sample and the aperture and reaches the second power meter (power meter 2), which measures its power as the signal power. The diameter of the used aperture was $1.5 \mathrm{~mm}$ in the acceptable range for diameter of apertures in Z-scan measurements [59]. The one-dimensional translation stage moves the position of the sample along the optical axis (the Z-axis). The normalized transmittance $T$ was continuously measured by calculating the ratio of signal to reference beam powers. The Z-scan measurement system components were placed on a firm optical bench to reduce the adverse vibration noise effects. The measurements were also made in the dark environment to minimize the noise from the interference of extraneous light.

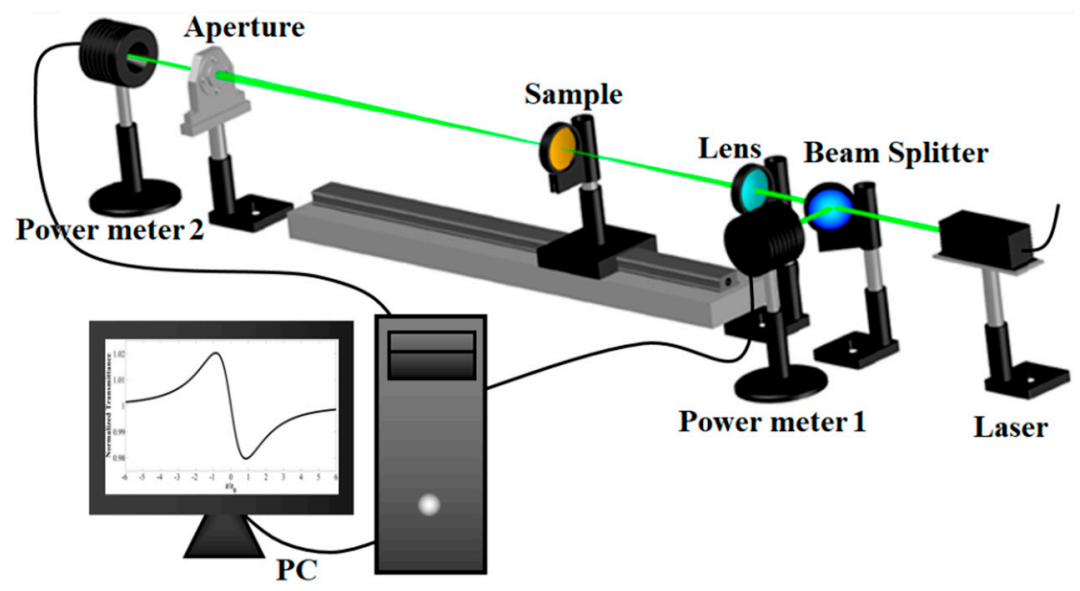

Figure 2. Scheme of the employed Z-scan system for measuring the nonlinear optical (NLO) properties. 
Theoretically, at high-intensity fields near the focal point of the converging lens, the sample behaves like a feeble lens whose focal length is proportional to the nonlinear refractive index $n_{2}$ of the sample and the position along the $Z$ axis [60]. In the so-called closed-aperture Z-scan, the presence of the far-field aperture enables the setup to analyze the tiny distortions induced by this weak $n_{2}$-dependent lens in the signal beam [61]. By lateral displacement of the aperture from the beam propagation axis, the open-aperture configuration, the nonlinear absorption coefficient will be measured by recording the entire signal beam. Without the aperture, the induced tiny distortions by the feeble $n_{2}$-dependent lens are insignificant and the changes of the signal beam power are only due to the NLO absorption of the sample [62]. The required curve equations for fitting on the normalized transmittance data and finding the NLO constants [63] can be theoretically obtained by describing the propagation of laser beam in the lens-like media by a suitable model [64].

\section{Results and Discussion}

For morphological characterization of the fabricated CNPs by SEM and TEM analyses, NPs colloidal solution was dried on laboratory slides. As shown in Figure $3 a-c, C N P s$ have been successfully formed in irregular spherical shapes due to the LAL process. Furthermore, the EDX spectra were utilized to analyze the presence of elements (Figure 4). As shown in Figure $4 \mathrm{a}, \mathrm{b}$, the synthesized sample has more amount of $\mathrm{C}$ element compared with laboratory slide.
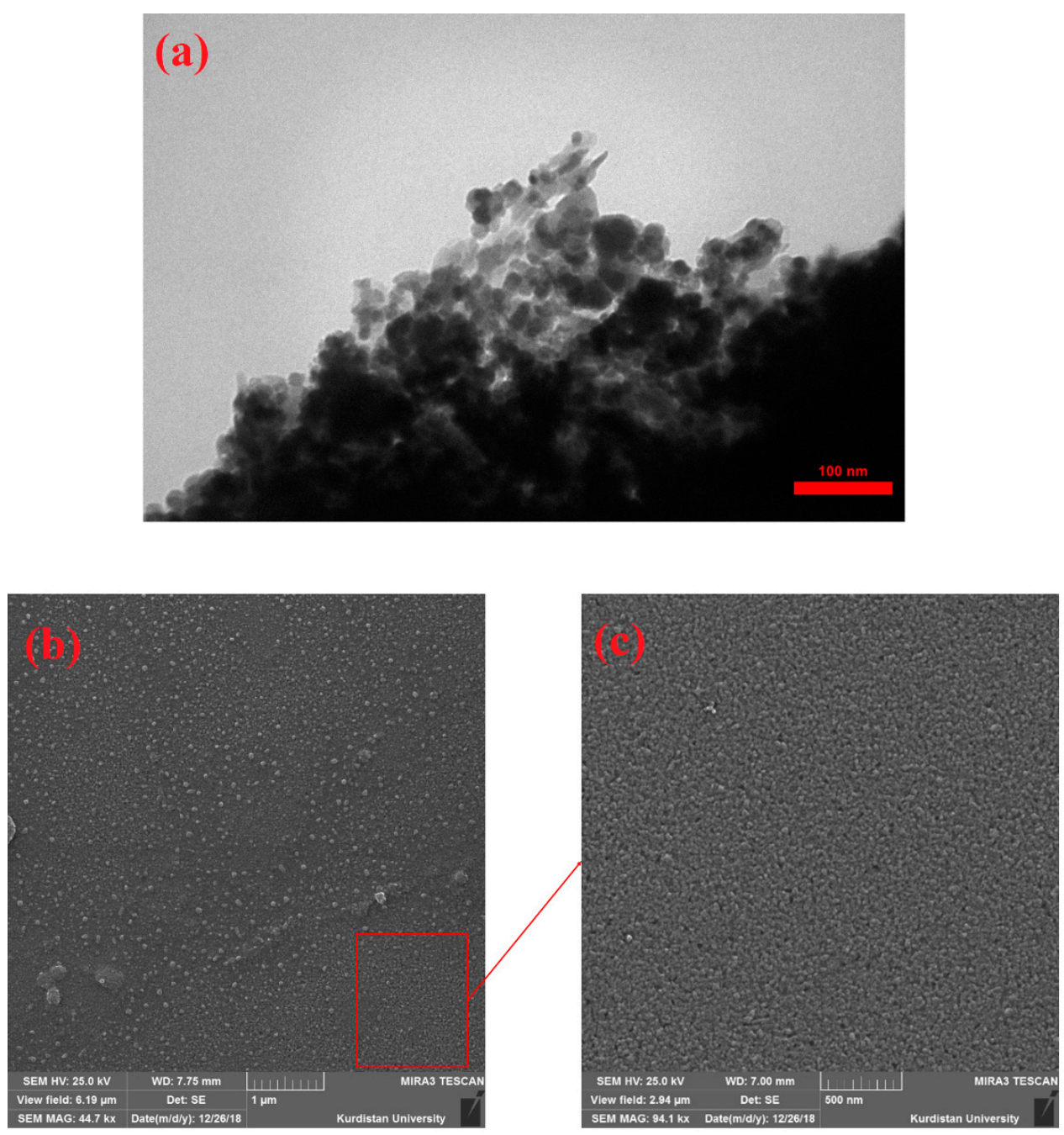

Figure 3. (a) TEM and (b,c) SEM images. 

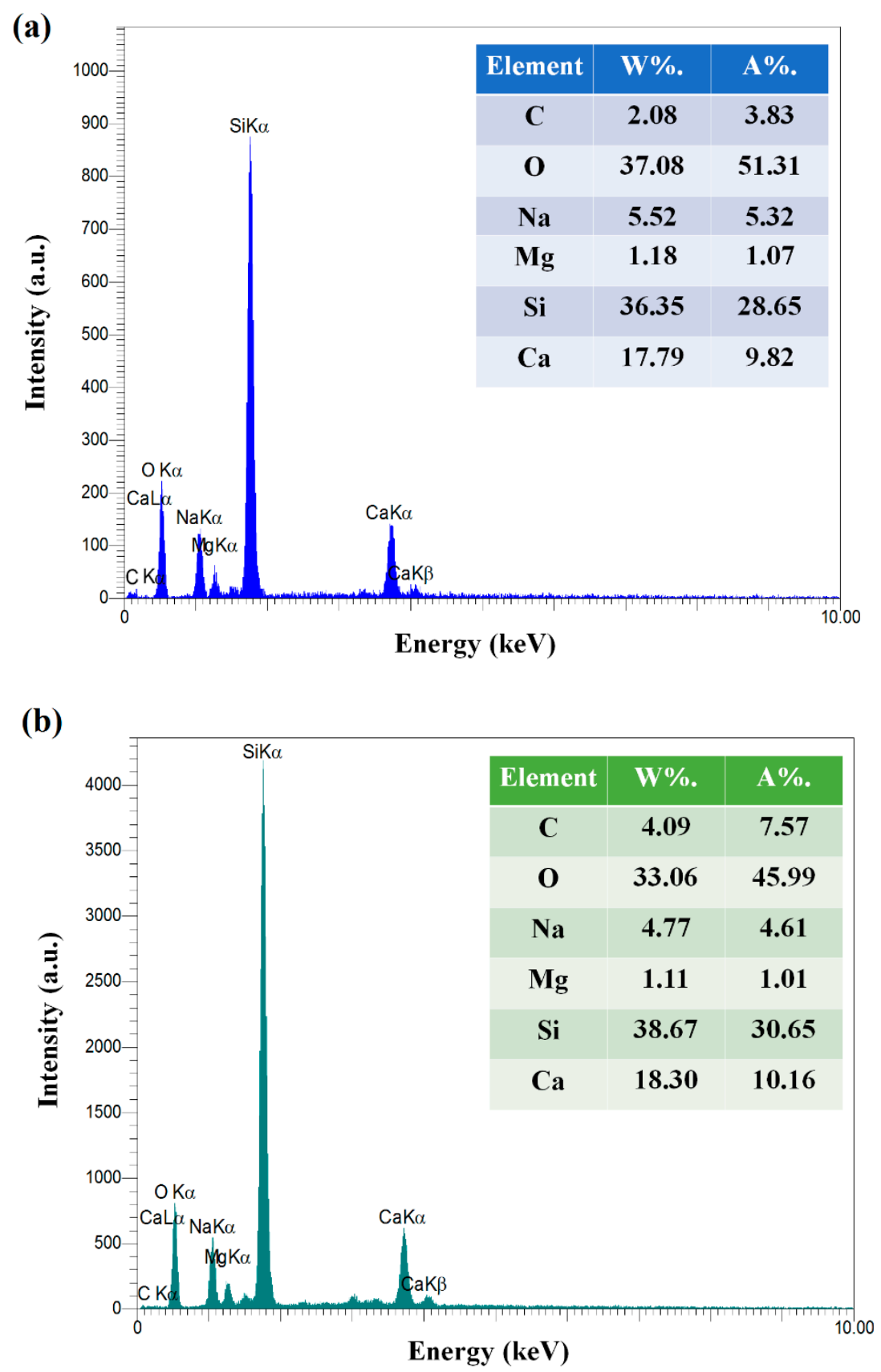

Figure 4. Energy-dispersive X-ray spectroscopy (EDX) spectra of (a) laboratory slide and (b) CNPs.

UV-Vis and fluorescence (FL) spectra were recorded to study the linear optical properties of the synthesized CNPs. Figure 5 demonstrates the UV-Vis spectrum of the CNPs suspension. Generally, CNPs have absorption peaks in the range of $180-280 \mathrm{~nm}$ [5]. According to Figure 5, three absorption peaks appear at $227 \mathrm{~nm}, 252 \mathrm{~nm}$, and $260 \mathrm{~nm}$, which are related to the $\pi-\pi^{*}$ transition of $\mathrm{C}=\mathrm{C}$ bonds in CNPs [43]. The weak absorption peaks at around $300 \mathrm{~nm}$ appear probably due to n-heptane molecules or their decomposition [12]. In addition, the obtained UV-Vis spectra of CNPs has more number of absorption peak compared with UV-Vis spectra of the prepared CNPs by LAL method in water $[65,66]$. 


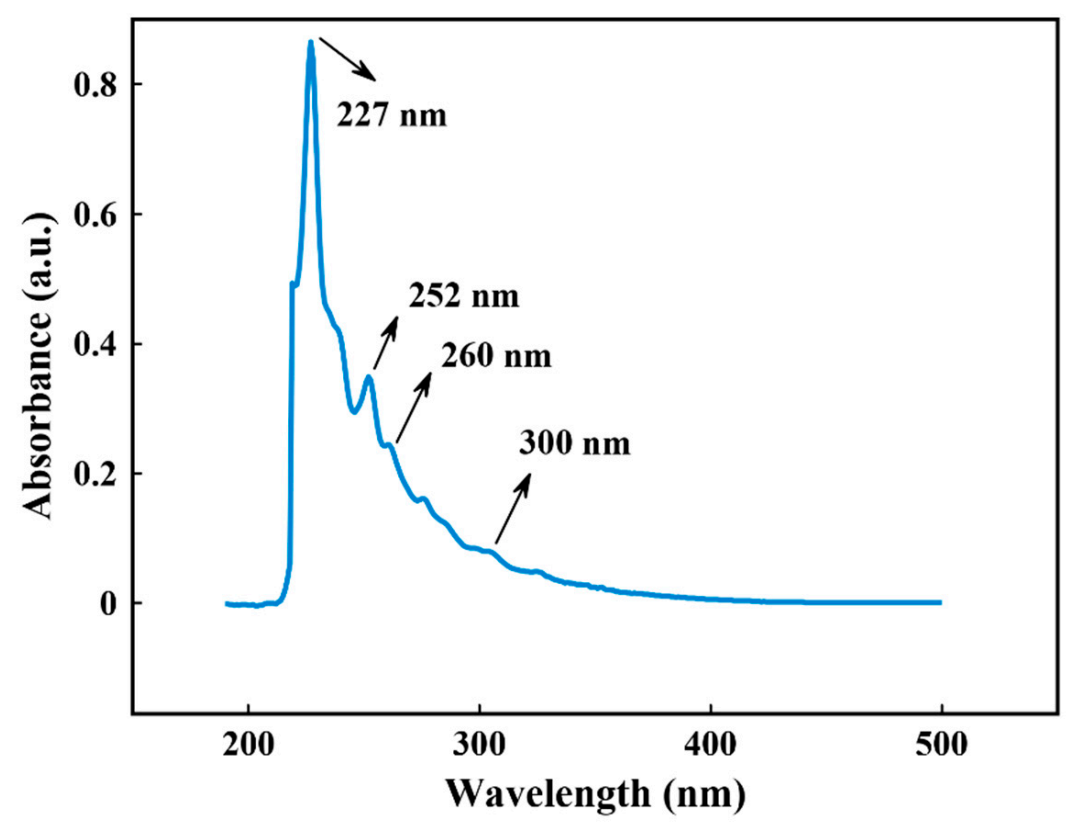

Figure 5. UV-Vis absorption spectrum of the CNPs suspension.

The CNPs FL emission spectra at different excitation wavelengths were recorded. The results are shown in Figure 6 and listed in Table 2. It is clear that the maximum FL emission of CNPs is at $436 \mathrm{~nm}$ by exciting the sample at the wavelength of $360 \mathrm{~nm}$. Moreover, a red shift can be discerned in the maximum FL emission of the sample by increasing the excitation wavelength. The peak intensity also decreases by increasing the excitation wavelength. Therefore, the FL emission of CNPs depends on the excitation wavelength, which is known to be due to the inherent size effect of CNPs [67].

Table 2. The fluorescence wavelength at different excitation wavelength.

\begin{tabular}{cc}
\hline Excitation Wavelength $(\mathbf{n m})$ & Fluorescence Wavelength $(\mathbf{n m})$ \\
\hline 320 & 395 \\
340 & 421 \\
360 & 435 \\
372 & 442 \\
380 & 449 \\
420 & 477 \\
440 & 494 \\
460 & 514 \\
\hline
\end{tabular}

DLS measurements determined the size and size distribution of the fabricated CNPs. As shown in Figure 7, the size of suspended CNPs in n-heptane is in the range of 2-4 nm and $18-28 \mathrm{~nm}$, and their average size is $23.84 \mathrm{~nm}$. 

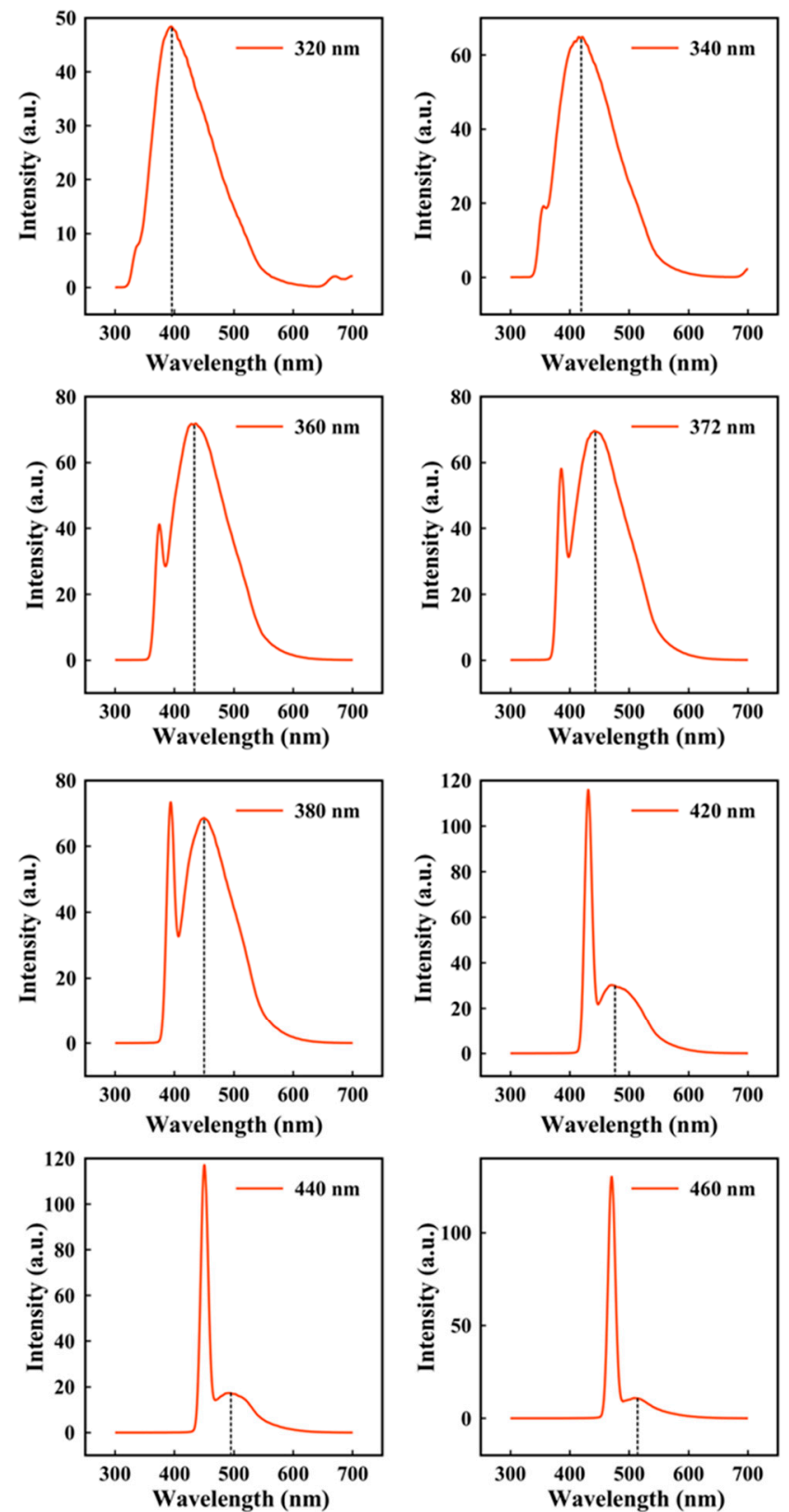

Figure 6. Fluorescence emission spectra of the prepared CNPs at various excitation wavelength.

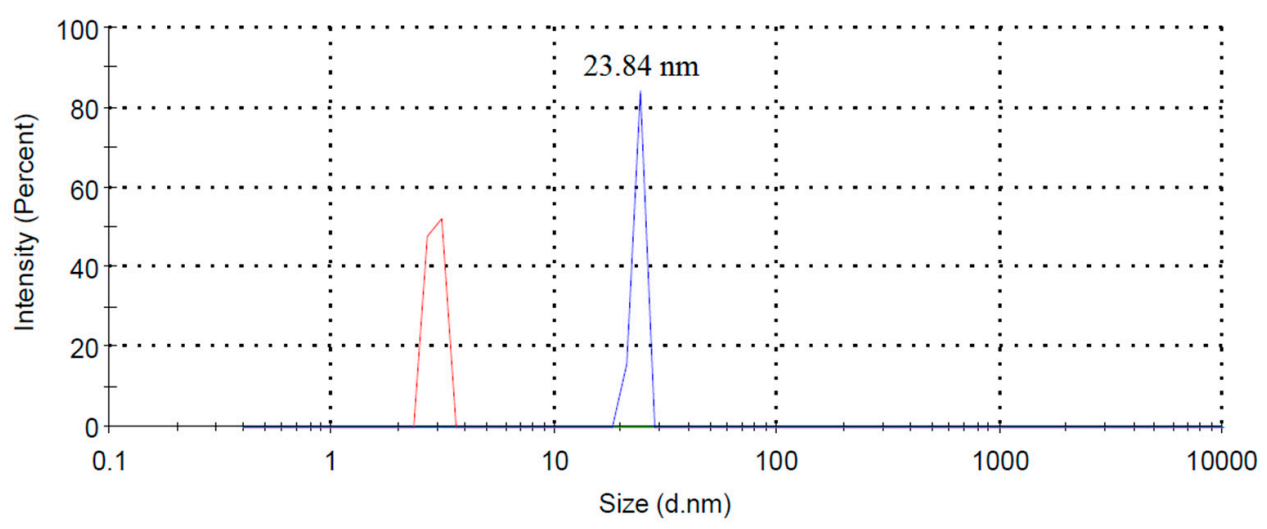

Figure 7. Size distribution of the synthesized CNPs. 
To study the structural properties, Raman characterization of the laboratory slide, AC, and the fabricated sample were performed at room temperature. The obtained results are shown in Figure 8. As can be verified, two peaks at approximately $1340 \mathrm{~cm}^{-1}$ and $1600 \mathrm{~cm}^{-1}$ are observable for $A C$ spectrum, which are related to the $D$ (the diamond) and the $G$ (the graphitic) bands, respectively [68]. The D band of CNPs appeared at about $1350 \mathrm{~cm}^{-1}$, and the intensity of both $D$ and $G$ bands was reduced after laser irradiation. The $D$ and the $\mathrm{G}$ bands have appeared due to the $\mathrm{Sp}^{3}$-bonded structure and the $\mathrm{Sp}^{2}$ bonds vibrations, respectively $[68,69]$. Compared with the synthesized CNPs in water, the intensity difference between D and G bands is lower [69], suggesting that the decomposition of n-heptane as an organic solvent may be enhanced which lead to carbon species fabrication [70].

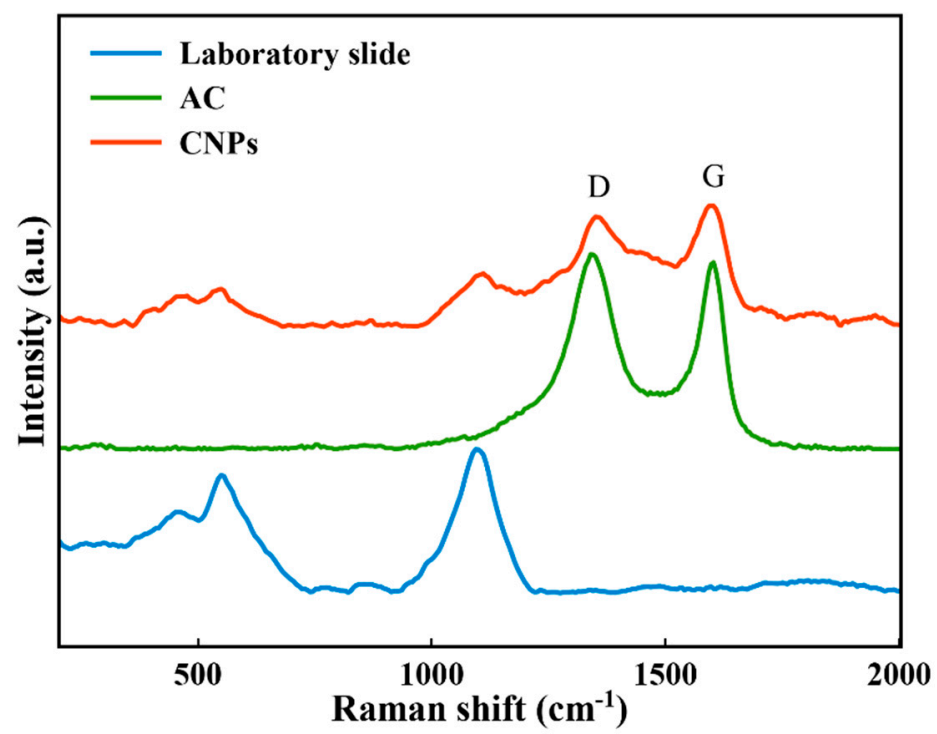

Figure 8. Raman spectra of the laboratory slide, activated carbon (AC), and the fabricated CNPs.

The Z-scan technique determined NLO coefficients of the CNPs. Figure 9 shows the results of open- and closed-aperture Z-scan measurements. The next equation was used for fitting the open-aperture data and finding the value of $\beta$ [71,72]:

$$
T_{\text {open }}(z)=\frac{\ln \left(1+q_{0}\right)}{q_{0}}
$$

With

$$
q_{0}=\frac{\beta I_{0} L_{\text {eff }}}{1+x^{2}}
$$

where $x=z / z_{0}$ and $L_{\text {eff }}=\left(1-\exp \left(-\alpha_{0} L\right)\right) / \alpha_{0}$ is the effective thickness, with $\alpha_{0}$ and $\mathrm{L}$ being the linear absorption coefficient and the sample real thickness, respectively. $z_{0}$ and $I_{0}$ are also the Rayleigh length and the on-axis intensity at the focus of the converging lens.

Visual inspection of Figure $9 \mathrm{~b}$ indicates the asymmetric shape of the Z-scan curve, which implies the large NLO response of the prepared CNPs. When this is the case, the general Z-scan theory based on the small phase shift approximation [57] cannot well fit the measured data, and an extended Z-scan theory should be used instead [72]. Therefore, the next equation was applied as the fitting function for determining the value of $\mathrm{n}_{2}$ [72]:

$$
T_{\text {closed }}(z)=\frac{1}{1-\frac{(4 x-\eta)}{\left(1+x^{2}\right)^{2}\left(1+q_{0}\right)} \Delta \Phi_{0}+\frac{\left(4+\eta^{2}\right)}{\left(1+x^{2}\right)^{3}\left(1+q_{0}\right)^{2}} \Delta \Phi_{0}^{2}}
$$

where $\eta=\beta /\left(2 \mathrm{k} n_{2}\right)$ and $\Delta \Phi_{0}=\mathrm{k} n_{2} I_{0} L_{\text {eff }}$. Hence, after extracting the value of $\beta$ by fitting Equation (1) on the open-aperture data, the value of $n_{2}$ was obtained using Equation 
(3) as the fitting function for closed-aperture results Z-scan measurements. Nonlinear least-squares analysis was implemented in MATLAB for fitting these two equations on the $z$-scan experimental data. The extracted values of $\beta$ and $n_{2}$ for the synthesized CNPs are listed in Table 3.

Table 3. The NLO constants $\mathrm{n}_{2}$ and $\beta$ of the synthesized CNPs.

\begin{tabular}{cc}
\hline $\mathbf{n}_{\mathbf{2}}\left(\mathrm{cm}^{2} / \mathbf{W}\right)$ & $\boldsymbol{\beta}(\mathbf{c m} / \mathbf{W})$ \\
\hline$-1.15 \pm 0.09 \times 10^{-9}$ & $1.49 \pm 0.11 \times 10^{-4}$ \\
\hline
\end{tabular}

(a)

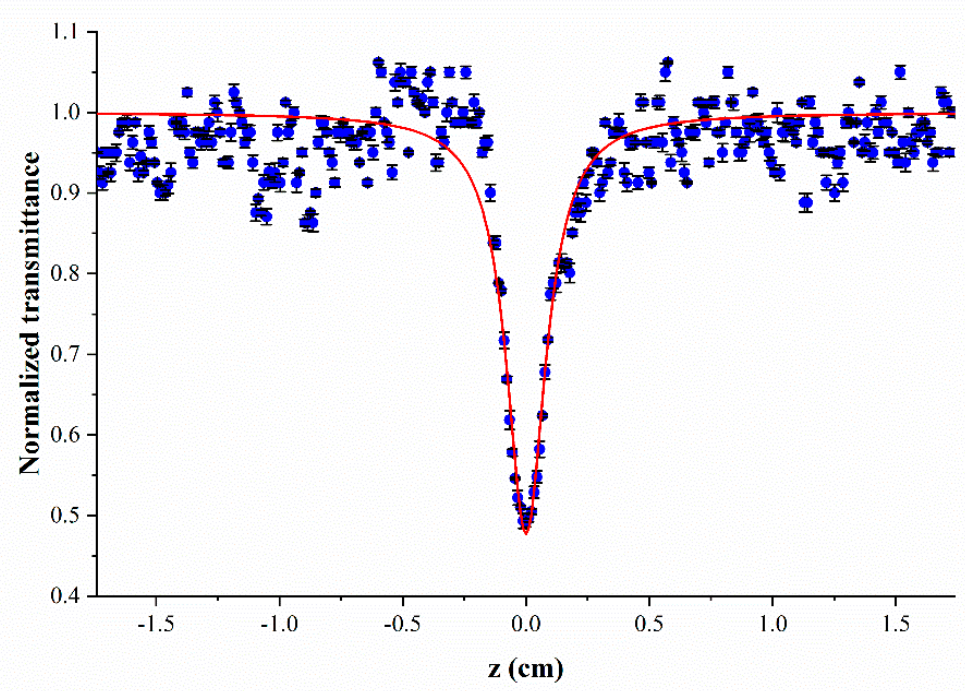

(b)

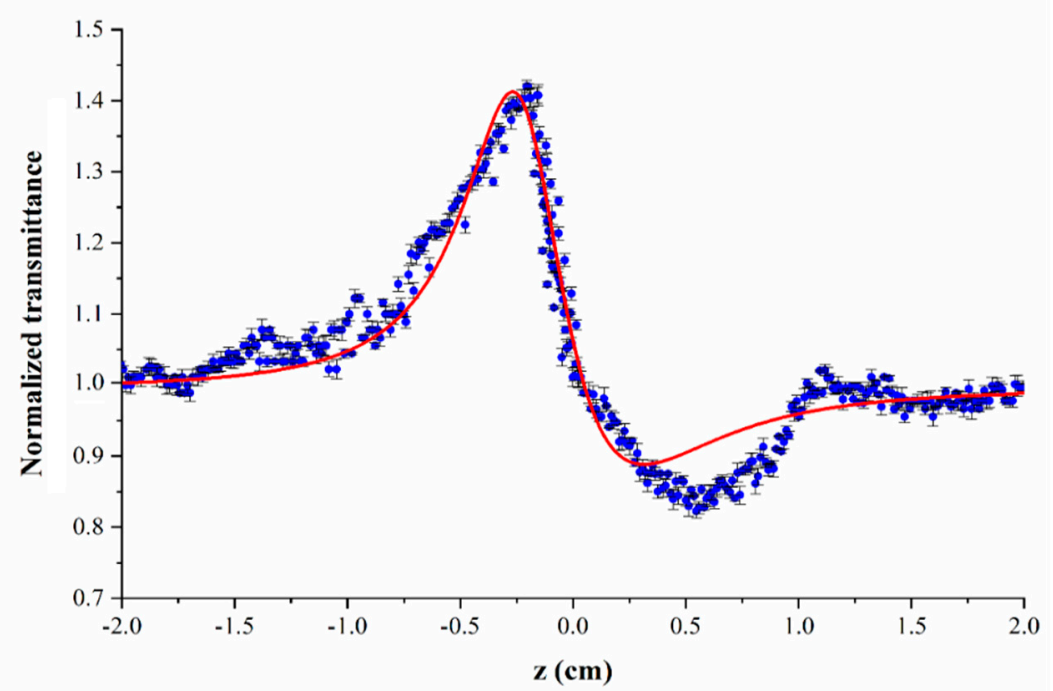

Figure 9. (a) open- and (b) closed-aperture Z-scan data points of the synthesized CNPs associated with their fitting curves.

The positive value of $\beta$ is compatible with the observable valley in the open-aperture signal in Figure 9a and indicates that reverse saturable absorption is the dominant nonlinear absorption mechanism in CNPs, which is consistent with a number of previous reports $[33-35,38,40,73]$. The observed strong reverse saturable absorption response of 
the synthesized AC CNPs in this work elucidates how they can be promising candidates for optical limiting applications. The negative value of the nonlinear refractive index in Table 2 is also compatible with the discernible peak-valley configuration (i.e., a pre-focal transmission maximum followed by the post-focal transmission minimum) in Figure $9 b$, which is also consistent with some previous studies [33,40].

The presence of $\pi$-electrons that can delocalize within the backbone of the organic compounds is considered the major reason for observation of NLO properties in these materials [74,75]. NLO properties that originate from $\pi$-electrons of $\mathrm{sp}^{2}$ hybridized carbon in graphene and its derivatives have also attracted great interest [76,77]. Regarding the CNPs, it is recently shown that their NLO properties are caused by induction of higher absorption cross sections of the excited-states by $\pi$-conjugated structure [35] and the ratio of $\mathrm{sp}^{2}$ and sp $\mathrm{s}^{3}$ bonded carbon atoms [33]. As it is indicated before, the $\mathrm{D}$ and the $\mathrm{G}$ bands in Figure 8 are due to the $\mathrm{Sp}^{3}$ and the $\mathrm{Sp}^{2}$ bond vibrations, respectively. As can be verified in this figure, the $\mathrm{Sp}^{2}$ carbon atoms are dominant in the laser fabricated AC CNPs, explaining the large optical nonlinearities observed in this material.

\section{Conclusions}

Due to their favorable characteristics, CNPs are now widely used in various fields such as biological imaging, drug delivery, fluorescent sensor design, multicolor LED production, energy conversion, and storage, etc. [78]. Indeed, the low cost and synthesis facility of CNPs have made them promising nanomaterials for optoelectronic and photonic applications. In this paper, for the first time to our knowledge, it is shown that the synthesized AC CNPs exhibit large NLO refractivity and absorption by excitation with $442 \mathrm{~nm}$ laser radiation. The present results indicate that AC CNPs are also very promising candidates for designing NLO devices and for various other photonic applications. We expect this first study on the NLO properties of the AC CNPs to foster several other groups investigating the NLO properties of AC CNPs with other laser excitation characteristics. Uncovering the underlying physical mechanisms in the NLO response with more details and functionalization of the AC CNPs in NLO devices are the other directions that can be followed up in future studies.

Author Contributions: Conceptualization, B.J.; experiments and analysis, H.G.G. and M.R.R.V.; writing—original draft preparation, B.J., M.E., Y.O., M.R.R.V. and H.G.G.; writing—review and editing B.J., Y.O. and M.R.R.V.; funding acquisition, Y.O.; Revision and editing. All authors have read and agreed to the published version of the manuscript.

Funding: This research was funded by grant numbers 163020139, 164020247, 163020816 and 163020211.

Data Availability Statement: Not available data.

Acknowledgments: The authors hereby express their thanks for the support rendered by Nanjing Forestry University and Bu Ali Sina university.

Conflicts of Interest: The authors declare no conflict of interest.

\section{References}

1. Khashan, K.; Jabir, M.; Abdulameer, F. In Preparation and characterization of copper oxide nanoparticles decorated carbon nanoparticles using laser ablation in liquid. J. Phys. Conf. Ser. 2018, 1003, 012100. [CrossRef]

2. Karimi-Maleh, H.; Shojaei, A.F.; Tabatabaeian, K.; Karimi, F.; Shakeri, S.; Moradi, R. Simultaneous determination of 6mercaptopruine, 6-thioguanine and dasatinib as three important anticancer drugs using nanostructure voltammetric sensor employing Pt/MWCNTs and 1-butyl-3-methylimidazolium hexafluoro phosphate. Biosens. Bioelectron. 2016, 86, 879-884. [CrossRef] [PubMed]

3. Asadian, E.; Ghalkhani, M.; Shahrokhian, S. Electrochemical sensing based on carbon nanoparticles: A review. Actuators B Chem. 2019, 293, 183-209. [CrossRef]

4. Karimi-Maleh, H.; Arotiba, O.A. Simultaneous determination of cholesterol, ascorbic acid and uric acid as three essential biological compounds at a carbon paste electrode modified with copper oxide decorated reduced graphene oxide nanocomposite and ionic liquid. J. Colloid. Interface Sci. 2020, 560, 208-212. [CrossRef] [PubMed] 
5. Yogesh, G.K.; Shuaib, E.; Sastikumar, D. Photoluminescence properties of carbon nanoparticles synthesized from activated carbon powder (4\% ash) by laser ablation in solution. Mater. Res. Bull. 2017, 91, 220-226. [CrossRef]

6. Tahernejad-Javazmi, F.; Shabani-Nooshabadi, M.; Karimi-Maleh, H. Analysis of glutathione in the presence of acetaminophen and tyrosine via an amplified electrode with MgO/SWCNTs as a sensor in the hemolyzed erythrocyte. Talanta 2018, 176, 208-213. [CrossRef]

7. Chen, Y.; Hu, Y.; Shen, Z.; Chen, R.; He, X.; Zhang, X.; Li, Y.; Wu, K. Hollow core-shell structured silicon@carbon nanoparticles embed in carbon nanofibers as binder-free anodes for lithium-ion batteries. J. Power Sources 2017, 342, 467-475. [CrossRef]

8. Shen, X.; Jiang, W.; Sun, H.; Wang, Y.; Dong, A.; Hu, J.; Yang, D. Ionic liquid assist to prepare Si@N-doped carbon nanoparticles and its high performance in lithium ion batteries. J. Alloy Compd. 2017, 691, 178-184. [CrossRef]

9. Liu, M.; Zhao, F.; Zhu, D.; Duan, H.; Lv, Y.; Li, L.; Gan, L. Ultramicroporous carbon nanoparticles derived from metal-organic framework nanoparticles for high-performance supercapacitors. Mater. Chem. Phy. 2018, 211, 234-241. [CrossRef]

10. Chen, X.; Sun, Y.; Liu, W. Template-assisted synthesized hollow sphere-like NiCoP/carbon nanoparticles composites for highperformance asymmetric supercapacitors. J. Electroanal. Chem. 2021, 880, 114862. [CrossRef]

11. Sedira, S.; Mendaci, B. Hydrothermal synthesis of spherical carbon nanoparticles (CNPs) for supercapacitor electrodes uses. Mater. Renew. Sustain. Energy 2020, 9, 1. [CrossRef]

12. Li, H.; Ming, H.; Liu, Y.; Yu, H.; He, X.; Huang, H.; Pan, K.; Kang, Z.; Lee, S.-T. Fluorescent carbon nanoparticles: Electrochemical synthesis and their $\mathrm{pH}$ sensitive photoluminescence properties. New J. Chem 2011, 35, 2666-2670. [CrossRef]

13. Chandra, S.; Das, P.; Bag, S.; Laha, D.; Pramanik, P. Synthesis, functionalization and bioimaging applications of highly fluorescent carbon nanoparticles. Nanoscale 2011, 3, 1533-1540. [CrossRef]

14. Orazbayev, S.; Zhunisbekov, A.; Ramazanov, T.; Omirbekov, D.; Dosbolayev, M.; Gabdullin, M.; Zhumadylov, R. Synthesis of carbon nanoparticles in combined RF-DC plasma. Mater. Today 2018, 5, 22819-22824. [CrossRef]

15. Kazemizadeh, F.; Malekfar, R.; Parvin, P. Pulsed laser ablation synthesis of carbon nanoparticles in vacuum. J. Phys. Chem. Solids 2017, 104, 252-256. [CrossRef]

16. Dudek, M.; Rosowski, A.; Koperkiewicz, A.; Grobelny, J.; Wach, R.; Sharp, M.; French, P.; Janasz, L.; Kozanecki, M. Carbon nanoparticles fabricated by infrared laser ablation of graphite and polycrystalline diamond targets. Phys. Status Solidi 2017, 214, 1600318. [CrossRef]

17. Semaltianos, N. Nanoparticles by laser ablation. Crit. Rev. Solid State Mater. Sci. 2010, 35, 105-124. [CrossRef]

18. Zhang, D.; Gökce, B.; Barcikowski, S. Laser synthesis and processing of colloids: Fundamentals and applications. Chem. Rev. 2017, 117, 3990-4103. [CrossRef] [PubMed]

19. Khashan, K.S.; Abdulameer, F.A.; Jabir, M.S.; Hadi, A.A.; Sulaiman, G.M. Anticancer activity and toxicity of carbon nanoparticles produced by pulsed laser ablation of graphite in water. Adv. Nat. Sci: Nanosci. Nanotechnol. 2020, 11, 035010.

20. Tian, X.; Zeng, A.; Liu, Z.; Zheng, C.; Wei, Y.; Yang, P.; Zhang, M.; Yang, F.; Xie, F. Carbon Quantum Dots: In vitro and in vivo Studies on Biocompatibility and Biointeractions for Optical Imaging. Int. J. Nanomed. 2020, 15, 6519. [CrossRef]

21. Hu, S.; Dong, Y.; Yang, J.; Liu, J.; Cao, S. Simultaneous synthesis of luminescent carbon nanoparticles and carbon nanocages by laser ablation of carbon black suspension and their optical limiting properties. J. Mater. Chem. 2012, 22, 1957-1961. [CrossRef]

22. Małolepszy, A.; Błonski, S.; Chrzanowska-Giżyńska, J.; Wojasiński, M.; Płocinski, T.; Stobinski, L.; Szymanski, Z. Fluorescent carbon and graphene oxide nanoparticles synthesized by the laser ablation in liquid. Appl. Phys. A 2018, 124, 282. [CrossRef]

23. Mohazzab, B.F.; Jaleh, B.; Kakuee, O.; Fattah-Alhosseini, A. Formation of titanium carbide on the titanium surface using laser ablation in n-heptane and investigating its corrosion resistance. Appl. Surf. Sci. 2019, 478, 623-635. [CrossRef]

24. Zeng, H.; Du, X.W.; Singh, S.C.; Kulinich, S.A.; Yang, S.; He, J.; Cai, W. Nanomaterials via laser ablation/irradiation in liquid: A review. Adv. Funct. Mater. 2012, 22, 1333-1353. [CrossRef]

25. Marsh, H.; Reinoso, F.R. Activated Carbon; Elsevier: Amsterdam, The Netherlands, 2006.

26. Ao, W.; Fu, J.; Mao, X.; Kang, Q.; Ran, C.; Liu, Y.; Zhang, H.; Gao, Z.; Li, J.; Liu, G. Microwave assisted preparation of activated carbon from biomass: A review. Renew. Sust. Energ. Rev. 2018, 92, 958-979. [CrossRef]

27. Mohan, M.; Sharma, V.K.; Kumar, E.A.; Gayathri, V. Hydrogen storage in carbon materials-A review. Energy Stor. 2019 , 1, e35. [CrossRef]

28. Tanaka, H.; Kränkel, C.; Kannari, F. Transition-metal-doped saturable absorbers for passive Q-switching of visible lasers. Opt. Mater. Express 2020, 10, 1827-1842. [CrossRef]

29. Lundén, H.; Glimsdal, E.; Lindgren, M.; Lopes, C. How to assess good candidate molecules for self-activated optical power limiting. Opt. Eng. 2018, 57, 030802. [CrossRef]

30. Bae, K.; Zhu, J.; Wolenski, C.; Das, A.; Horning, T.M.; Pampel, S.; Grayson, M.B.; Zohrabi, M.; Gopinath, J.T.; Park, W. Indium Tin Oxide Nanoparticle-Coated Silica Microsphere with Large Optical Nonlinearity and High Quality Factor. ACS Photonics 2020, 7 , 3042-3048. [CrossRef]

31. Dorfer, C.; Hits, D.; Kasmi, L.; Kramberger, G.; Lucchini, M.; Mikuž, M.; Wallny, R. Three-dimensional charge transport mapping by two-photon absorption edge transient-current technique in synthetic single-crystalline diamond. Appl. Phys. Lett 2019, 114, 203504. [CrossRef]

32. Ewart, P. Encyclopedia of Modern Optics. In SPECTROSCOPY I Nonlinear Laser Spectroscopy; Elsevier: Amsterdam, The Netherlands, 2005; pp. 109-119. 
33. Papagiannouli, I.; Bourlinos, A.B.; Bakandritsos, A.; Couris, S. Nonlinear optical properties of colloidal carbon nanoparticles: Nanodiamonds and carbon dots. RSC Adv. 2014, 4, 40152-40160. [CrossRef]

34. Zhu, S.; Wang, K.; Hu, J.; Liu, R.; Zhu, H. Nitrogen and sulphur co-doped carbon quantum dots and their optical power limiting properties. Mater. Adv. 2020, 1, 3176-3181. [CrossRef]

35. Yin, K.; Lu, D.; Tian, W.; Zhang, R.; Yu, H.; Gorecka, E.; Pociecha, D.; Godbert, N.; Hao, J.; Li, H. Ordered Structures of Alkylated Carbon Dots and Their Applications in Nonlinear Optics. J. Mater. Chem. C 2020, 8, 8980-8991. [CrossRef]

36. Bourlinos, A.B.; Trivizas, G.; Karakassides, M.A.; Baikousi, M.; Kouloumpis, A.; Gournis, D.; Bakandritsos, A.; Hola, K.; Kozak, O.; Zboril, R. Green and simple route toward boron doped carbon dots with significantly enhanced non-linear optical properties. Carbon 2015, 83, 173-179. [CrossRef]

37. Ma, L.; Xiang, W.; Gao, H.; Wang, J.; Ni, Y.; Liang, X. Facile synthesis of tunable fluorescent carbon dots and their third-order nonlinear optical properties. Dyes Pigm. 2016, 128, 1-7. [CrossRef]

38. Vijesh, K.; Musfir, P.; Thomas, T.; Vaishakh, M.; Nampoori, V.; Thomas, S. Enhanced nonlinear optical properties of solution dispersed carbon dots decorated graphene oxide with varying viscosity. Opt. Laser Technol. 2020, 121, 105776. [CrossRef]

39. Wang, X.; Bai, L.; Shen, L.; Yao, B.; Huang, H.; Liu, Y.; Song, Y.; Kang, Z. Nonlinear optical switching behavior of nitrogen-doped carbon dots. Opt. Mater. 2019, 95, 109216. [CrossRef]

40. Bai, L.; Qiao, S.; Li, H.; Fang, Y.; Yang, Y.; Huang, H.; Liu, Y.; Song, Y.; Kang, Z. N-Doped carbon dot with surface dominant non-linear optical properties. RSC Adv. 2016, 6, 95476-95482. [CrossRef]

41. Gao, M.; Chang, Q. AOPC 2015: In Advances in Laser Technology and Applications. In Nonlinear Absorption Characteristics of Carbon Quantum Dots; SPIE: Bellingham, WA, USA, 2015; p. 96710A.

42. Reyes-Contreras, D.; Camacho-López, M.; Camacho-López, M.A.; Camacho-López, S.; Rodríguez-Beltrán, R.I.; Mayorga-Rojas, M. Influence of the per pulse laser fluence on the optical properties of carbon nanoparticles synthesized by laser ablation of solids in liquids. Opt. Laser Technol. 2015, 74, 48-52. [CrossRef]

43. Meiling, T.T.; Cywiński, P.J.; Bald, I. White carbon: Fluorescent carbon nanoparticles with tunable quantum yield in a reproducible green synthesis. Sci. Rep. 2016, 6, 1-9. [CrossRef]

44. Sun, X.; He, J.; Meng, Y.; Zhang, L.; Zhang, S.; Ma, X.; Dey, S.; Zhao, J.; Lei, Y. Microwave-assisted ultrafast and facile synthesis of fluorescent carbon nanoparticles from a single precursor: Preparation, characterization and their application for the highly selective detection of explosive picric acid. J. Mater. Chem. A 2016, 4, 4161-4171. [CrossRef]

45. Roshni, V.; Ottoor, D. Synthesis of carbon nanoparticles using one step green approach and their application as mercuric ion sensor. J. Lumin. 2015, 161, 117-122. [CrossRef]

46. Huang, X.; Wu, S.; Du, X. Gated mesoporous carbon nanoparticles as drug delivery system for stimuli-responsive controlled release. Carbon 2016, 101, 135-142. [CrossRef]

47. Sharker, S.M.; Kim, S.M.; Lee, J.E.; Jeong, J.H.; In, I.; Lee, K.D.; Lee, H.; Park, S.Y. In situ synthesis of luminescent carbon nanoparticles toward target bioimaging. Nanoscale 2015, 7, 5468-5475. [CrossRef] [PubMed]

48. Zheng, P.; Liu, T.; Zhang, J.; Zhang, L.; Liu, Y.; Huang, J.; Guo, S. Sweet potato-derived carbon nanoparticles as anode for lithium ion battery. RSC Adv. 2015, 5, 40737-40741. [CrossRef]

49. Ngu, P.Z.Z.; Chia, S.P.P.; Fong, J.F.Y.; Ng, S.M. Synthesis of carbon nanoparticles from waste rice husk used for the optical sensing of metal ions. New Carbon Mater. 2016, 31, 135-143. [CrossRef]

50. Dekaliuk, M.; Pyrshev, K.; Demchenko, A. Visualization and detection of live and apoptotic cells with fluorescent carbon nanoparticles. J. Nanobiotechnol. 2015, 13, 1-8. [CrossRef]

51. Singh, V.; Mishra, A.K. Green and cost-effective fluorescent carbon nanoparticles for the selective and sensitive detection of iron (III) ions in aqueous solution: Mechanistic insights and cell line imaging studies. Sens. Actuators B Chem. 2016, 227, 467-474. [CrossRef]

52. Yu, C.; Xuan, T.; Chen, Y.; Zhao, Z.; Sun, Z.; Li, H. A facile, green synthesis of highly fluorescent carbon nanoparticles from oatmeal for cell imaging. J. Mater. Chem. C 2015, 3, 9514-9518. [CrossRef]

53. Yang, P.; Zhao, J.; Wang, J.; Cao, B.; Li, L.; Zhu, Z. Light-induced synthesis of photoluminescent carbon nanoparticles for Fe 3+ sensing and photocatalytic hydrogen evolution. J. Mater. Chem. A 2015, 3, 136-138. [CrossRef]

54. Arcudi, F.; Đorđević, L.; Prato, M. Synthesis, Separation, and Characterization of Small and Highly Fluorescent Nitrogen-Doped Carbon NanoDots. Angew. Chem. 2016, 128, 2147-2152. [CrossRef]

55. Jaleh, B.; Rouzbahani, M.G.; Abedi, K.; Azizian, S.; Ebrahimi, H.; Nasrollahzadeh, M.; Varma, R.S. Photocatalytic decomposition of VOCs by $\mathrm{AC}-\mathrm{TiO}_{2}$ and $\mathrm{EG}-\mathrm{TiO}_{2}$ nanocomposites. Clean Technol. Environ. Policy 2019, 21, 1259-1268. [CrossRef]

56. Sheik-Bahae, M.; Said, A.A.; Van Stryland, E.W. High-sensitivity, single-beam $\mathrm{n}_{2}$ measurements. Opt. Lett. 1989, $14,955-957$. [CrossRef]

57. Sheik-Bahae, M.; Said, A.A.; Wei, T.-H.; Hagan, D.J.; Van Stryland, E.W. Sensitive measurement of optical nonlinearities using a single beam. IEEE J. Quantum Electron. 1990, 26, 760-769. [CrossRef]

58. Van Stryland, E.W.; Sheik-Bahae, M. Characterization Techniques and Tabulations for Organic Nonlinear Optical Materials, 1st ed.; Routledge: London, UK, 2018; pp. 671-708.

59. MR, R.V. Role of the aperture in Z-scan experiments: A parametric study. Chin. Phys. B 2015, 24, 114206.

60. Vaziri, M.R. Comment on "Nonlinear refraction measurements of materials using the moiré deflectometry". Opt. Commun. 2015, 357, 200-201. [CrossRef] 
61. Omidvar, A.; RashidianVaziri, M.; Jaleh, B. Enhancing the nonlinear optical properties of graphene oxide by repairing with palladium nanoparticles. Phys. E Low Dimens. Syst. Nanostruct. 2018, 103, 239-245. [CrossRef]

62. Fakhri, P.; Vaziri, M.R.; Jaleh, B.; Shabestari, N.P. Nonlocal nonlinear optical response of graphene oxide-Au nanoparticles dispersed in different solvents. J. Opt. 2015, 18, 015502. [CrossRef]

63. Vaziri, M.R.R. Z-scan theory for nonlocal nonlinear media with simultaneous nonlinear refraction and nonlinear absorption. Appl. Opt. 2013, 52, 4843-4848. [CrossRef] [PubMed]

64. Vaziri, M.R. Describing the propagation of intense laser pulses in nonlinear Kerr media using the ducting model. Laser Phys 2013, 23, 105401. [CrossRef]

65. Ismail, R.A.; Mohsin, M.H.; Ali, A.K.; Hassoon, K.I.; Erten-Ela, S. Preparation and characterization of carbon nanotubes by pulsed laser ablation in water for optoelectronic application. Phys. E Low Dimens. Syst. Nanostruct. 2020, 119, 113997. [CrossRef]

66. Ganash, E.A.; Al-Jabarti, G.A.; Altuwirqi, R.M. The synthesis of carbon-based nanomaterials by pulsed laser ablation in water. Mater. Res. Express 2019, 7, 015002. [CrossRef]

67. Huang, H.; Lv, J.-J.; Zhou, D.-L.; Bao, N.; Xu, Y.; Wang, A.-J.; Feng, J.-J. One-pot green synthesis of nitrogen-doped carbon nanoparticles as fluorescent probes for mercury ions. RSC Adv. 2013, 3, 21691-21696. [CrossRef]

68. Le, K.C.; Lefumeux, C.; Pino, T. Differential Raman backscattering cross sections of black carbon nanoparticles. Sci Rep. 2017, 7, 1-9. [CrossRef]

69. Cárdenas, J.F.; Cadenbach, T.; Zhang, Z.-B.; Costa-Vera, C.; Debut, A.; Vaca, A.; Zhang, S.-L.; Paz, J. Raman spectroscopy of carbon nano-particles synthesized by laser ablation of graphite in water. Rev. Mex. Fis. 2017, 63, 71-75.

70. Zhang, D.; Zhang, C.; Liu, J.; Chen, Q.; Zhu, X.; Liang, C. Carbon-encapsulated metal/metal carbide/metal oxide core-shell nanostructures generated by laser ablation of metals in organic solvents. ACS Appl. Nano Mater. 2018, 2, 28-39. [CrossRef]

71. Zeinali, M.; Jaleh, B.; Vaziri, M.R.; Omidvar, A. Study of nonlinear optical properties of $\mathrm{TiO}_{2}$-polystyrene nanocomposite films. Quantum Electron. 2019, 49, 951. [CrossRef]

72. Kwak, C.H.; Lee, Y.L.; Kim, S.G. Analysis of asymmetric Z-scan measurement for large optical nonlinearities in an amorphous $\mathrm{As}_{2} \mathrm{~S}_{3}$ thin film. JOSA B 1999, 16, 600-604. [CrossRef]

73. Belousova, I.M.; Videnichev, D.A.; Kislyakov, I.M.; Krisko, T.K.; Rozhkova, N.N.; Rozhkov, S.S. Comparative studies of optical limiting in fullerene and shungite nanocarbon aqueous dispersions. Opt. Mater. Express 2015, 5, 169-175. [CrossRef]

74. De La Torre, G.; Vazquez, P.; Agullo-Lopez, F.; Torres, T. Role of structural factors in the nonlinear optical properties of phthalocyanines and related compounds. Chem. Rev. 2004, 104, 3723-3750. [CrossRef]

75. Barlow, S.; Marder, S.R. Nonlinear Optical Properties of Organic Materials; Wiley-VCH Verlag GmbH and Co. KGaA: Hoboken, NJ, USA, 2007.

76. Cao, L.; Sahu, S.; Anilkumar, P.; Kong, C.Y.; Sun, Y.-P. Linear and nonlinear optical properties of modified graphene-based materials. MRS Bull. 2012, 37, 1283. [CrossRef]

77. Wang, J.; Chen, Y.; Li, R.; Dong, H.; Ju, Y.; He, J.; Fan, J.; Wang, K.; Liao, K.-S.; Zhang, L. Graphene and carbon nanotube polymer composites for laser protection. J. Inorg. Organomet. Polym. Mater. 2011, 21, 736-746. [CrossRef]

78. Kang, C.; Huang, Y.; Yang, H.; Yan, X.F.; Chen, Z.P. A Review of Carbon Dots Produced from Biomass Wastes. Nanomaterials 2020, 10, 2316. [CrossRef] [PubMed] 